\title{
A comunicação pública como instrumento de desenvolvimento, democracia e construção de cidadania: análise das práticas de transparência e acesso à informação no Município de São Luís, MA
}

\author{
Public communication as an instrument for the development, democracy and \\ construction of citizenship: analysis of transparency practices and access to \\ information in the Municipality of São Luís, MA
}

\section{Comunicación pública como instrumento para el desarrollo, la democracia y la construcción de la ciudadanía: análisis de las prácticas de transparencia y acceso a la información en el Municipio de San Luís, MA}

\author{
Silvia Leticia Araújo de Melo ${ }^{1}$ \\ Monica Franchi Carniello ${ }^{2}$ \\ Recebido em: 26/02/2020; revisado e aprovado em: 21/08/2020; aceito em: 28/12/2020 \\ DOI: http://dx.doi.org/10.20435/inter.v22i3.2945
}

\begin{abstract}
Resumo: Na era contemporânea, a comunicação pública se estabelece por intermédio das tecnologias de informação e comunicação (TIC). Esta pesquisa teve como objetivo verificar a contribuição das TIC para o desenvolvimento de São Luís, capital do Estado do Maranhão, especificamente quanto ao acesso à informação. Realizou-se pesquisa de campo com aplicação de 384 questionários aos munícipes, para a percepção destes em relação à temática abordada, e entrevistas do tipo semiestruturada junto aos gestores municipais. Os resultados evidenciaram que o referido município carece de políticas educacionais que dotem e instrumentalizem seus cidadãos para o uso das TIC, bem como há pouca utilização do e-SIC, canal oficial adotado pelo município para pedidos de acesso à informação.
\end{abstract}

Palavras-chave: desenvolvimento; tecnologias de informação e comunicação; comunicação pública; acesso à informação.

Abstract: In the contemporary era, public communication is established through information and
communication technologies (ICT). This research aimed to verify the contribution of the ICT to the
development of São Luís, capital of Maranhão State, specifically regarding access to information. Field research
was conducted with questionnaires applied to 384 residents for their perception of the theme and semi-
structured interviews with municipal managers. The results showed that this municipality lacks educational
policies that provide and equip its citizens for the use of ICT, as well as there is little use of e-SIC, the official
channel adopted by the municipality for requests for access to information.

Keywords: development; information and communication technologies; public communication; access to information.

Resumen: En la era contemporánea, la comunicación pública se establece a través de las tecnologías de la información y la comunicación (TIC). Esta investigación tuvo como objetivo verificar la contribución de las tecnologías de la información y la comunicación (TIC) al desarrollo de São Luís, capital del estado de Maranhão, específicamente en relación con el acceso a la información. La investigación de campo se realizó con cuestionarios aplicados a 384 residentes para su percepción del tema y entrevistas semiestructuradas con gerentes municipales. Los resultados mostraron que este municipio carece de políticas educativas que brinden y equipan a sus ciudadanos para el uso de las TIC, y que el uso de e-SIC, el canal oficial adoptado por el municipio para las solicitudes de acceso a la información, es escaso.

Palabras clave: desarrollo; tecnologías de la información y la comunicación; comunicación pública; acceso a la información.

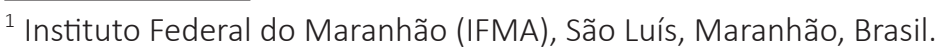

${ }^{2}$ Universidade de Taubaté (UNITAU), Taubaté, São Paulo, Brasil.
} 


\section{INTRODUÇÃO}

A comunicação acompanha a evolução do homem na sociedade. No mundo contemporâneo, a comunicação se estabelece por intermédio das tecnologias de informação e comunicação (TIC). Vive-se em uma sociedade marcada pela circulação de informações em tempo real e que aponta para uma nova visão de desenvolvimento, aliada ao papel das TIC, que impactam na vida das pessoas em todo o mundo, especialmente a internet e o telefone celular (KLEINE, 2013).

De igual modo, no âmbito da administração pública, a ação comunicacional ganha novos rumos com o advento das TIC, uma vez que o cenário midiático que está posto viabilizou os fluxos de comunicação entre governo e sociedade ao instituir diretrizes que contemplam a utilização de meios de comunicação executados por essas tecnologias, a exemplo dos canais disponibilizados pela administração pública, como sistema de ouvidoria e sistema eletrônico de informação ao cidadão (e-SIC).

Nesse sentido, esse novo papel da informação e do conhecimento vem provocando modificações substantivas nas relações, forma e conteúdo de trabalho (LASTRES; ALBAGLI, 1999). A sociedade em rede tem um usuário de serviço público que busca, cada vez mais, o acompanhamento dos atos governamentais como forma de consolidar um desenvolvimento sustentável à medida que almeja a garantia de direitos e a transparência da administração pública.

Apresenta-se, nesse rol de direitos, o acesso às informações públicas. Partindo do pressuposto de que todo cidadão bem informado estará mais apto a conhecer e reivindicar outros direitos fundamentais, como educação, segurança e saúde, faz-se necessário o estímulo cada vez mais cedo a essa prática, com vistas à formação de cidadãos críticos, ciente de seus direitos e deveres.

Justifica-se a temática considerando que, historicamente, o acesso à informação sempre esteve restrito a grupos seletos, defensores do sigilo como regra. A Constituição Federal Brasileira de 1988 (OLIVEIRA, 2002) foi o marco regulatório para o controle social do país, evidenciando uma democracia com ampla previsão de direitos. A partir disso, a participação popular nas ações governamentais voltadas para o bem comum imprimiu os princípios da administração pública: legalidade, publicidade, impessoalidade, moralidade e transparência.

Este artigo teve por objetivo verificar a contribuição das tecnologias de informação e comunicação (TIC) para o desenvolvimento de São Luís, capital do Estado do Maranhão (MA), especificamente quanto ao acesso à informação. Para tal, traçou-se um percurso de pesquisa que caracterizou a gestão municipal de São Luís quanto à estrutura e gestão da comunicação; verificou-se o uso das TIC por parte da gestão, visando ao acesso à informação; compreendeu-se como o processo de comunicação pública implantado no município, à luz das TIC, foi capaz de promover ou instigar o cidadão na busca pelo acesso à informação; e constatou-se a publicidade dos mecanismos de transparência ativa no site oficial do município e sua relação com a atitude cidadã.

Os conteúdos aqui explanados foram elaborados de forma a ser apresentados em seções. Na primeira seção, destaca-se a relação entre comunicação e desenvolvimento, subdividida em: O uso das TIC para a promoção do desenvolvimento; Comunicação Pública; e As TIC na Administração Pública. A segunda seção aborda as percepções dos munícipes em relação ao acesso à informação, e a terceira seção, por sua vez, apresenta a percepção dos gestores em relação ao objeto de estudo da pesquisa. 


\section{COMUNICAÇÃO E DESENVOLVIMENTO}

A comunicação é vista como algo inerente ao ser humano e vai sofrendo modificações à medida que o homem busca suprir as suas necessidades. Na era contemporânea, a comunicação ganha uma nova roupagem, tendo em vista que o homem se encontra inserido em uma sociedade na qual dispõe de diversos meios para se comunicar. Nesse processo, a informação e a comunicação desempenham um papel cada vez mais central. Expressões como a era da comunicação e sociedade da informação tornaram-se frequentes para além dos círculos acadêmicos (NEULS, 2011).

Visto que o desenvolvimento de um território é concebido atualmente de forma multidimensional, representado pelo tripé economia, sociedade e meio ambiente, faz-se necessário conhecer as especificidades desse espaço para o planejamento das ações, levando em consideração suas características, com ênfase na qualidade de vida dos indivíduos que o integram e na constante busca da sustentabilidade e da igualdade social.

Furtado (1983) defende que um território deve assumir a sua situação histórica e abrir caminho para o futuro a partir do conhecimento de sua realidade. Para tanto, a primeira condição para libertar-se do subdesenvolvimento que assola a maioria das populações é escapar da obsessão de reproduzir o perfil daqueles que se autointitulam desenvolvidos.

Diante dessa nova concepção em termos de abrangência da comunicação e, considerando, pois, que ela está intrinsicamente ligada ao desenvolvimento, Sen (2000) destaca condições necessárias para instituir processos de desenvolvimento nas sociedades contemporâneas, rompendo a visão restrita que conceitua desenvolvimento apenas como acumulação de riqueza. Assim, ele defende que o desenvolvimento consiste na eliminação de privações de liberdade que limitam as escolhas e as oportunidades das pessoas de exercer ponderadamente sua condição de agente.

Kleine (2013), corroborando com Sen, defende que o desenvolvimento está relacionado com a abordagem das capacidades, aliada ao papel das TIC, responsável pelo surgimento, segundo ela, de uma nova área de estudo: Informação e Comunicação para o Desenvolvimento. Essa vertente da comunicação surgiu na década de 1940, logo após o fim da 2ạ Guerra Mundial.

Nora Quebral, da Universidade das Filipinas, foi a pioneira nos estudos sobre Comunicação para o Desenvolvimento, autora da obra Development Comunication, de 1972. Ela definia essa área de estudo como a arte e a ciência da comunicação humana aplicadas à rápida transformação de um país de um estado de pobreza a uma condição dinâmica de crescimento econômico, que possibilite maior equidade econômica e social e maior realização do potencial humano (QUEBRAL, 2002).

Ao longo do tempo, o campo da comunicação para o desenvolvimento vem evoluindo, sempre focado nas pessoas como agentes de desenvolvimento e de mudanças, vislumbrando o progresso econômico e tecnológico, mas sobretudo o crescimento integral das pessoas como protagonistas e beneficiárias dos processos de desenvolvimento (PERUZZO, 2015).

No âmbito da administração pública, Zémor (2009) defende que a comunicação pública é a troca e o compartilhamento de informações de interesses gerais. Duarte (2007) diz que, quando há a oferta dos mais diversos canais ao cidadão, e este interage com o Estado, a comunicação pública cumpre o seu papel, devendo ser compreendida com sentido mais amplo do que dar informação. 
Constata-se, portanto, a relação intrínseca entre comunicação e desenvolvimento, que necessita ser pensada de forma multidimensional, a fim de que outros aspectos devam ser pautados para a efetiva melhoria da qualidade de vida social e econômica dos cidadãos de um país, buscando-se, sobretudo, justiça social em prol da coletividade, e não apenas para uma pequena parcela da população. Essa mudança qualitativa está diretamente ligada à sociedade de rede na era contemporânea. A comunicação nos dias atuais é marcada pela circulação instantânea de informações e tem nas TIC os meios necessários para instituir um diálogo democrático entre o cidadão e o Estado.

Em busca de compreender melhor a abordagem da comunicação para o desenvolvimento, Kleine (2013) defende o uso das Tecnologias de Informação e Comunicação para viabilizar o acesso à informação e, por conseguinte, ampliar o desenvolvimento, conforme será visto a seguir.

\subsection{0 uso das TIC para a promoção do desenvolvimento}

O processo de transformação digital vivenciado, principalmente a partir da década de 1990, trouxe mudanças significativas para toda a humanidade. A velocidade da informação é uma realidade no cotidiano das pessoas, viabilizada pelo uso das TIC: pode-se enviar um e-mail para vários destinatários, fazer uma ligação de chamada de vídeo, comunicar-se com uma empresa por meio das redes sociais. Esses são apenas alguns exemplos do poder incalculável da informação no mundo globalizado.

Lemos (2004, p. 79) diz que "[...] as novas tecnologias de informação e comunicação são resultado de convergências tecnológicas que transformam as antigas através de revisões, invenções ou junções". Pode-se afirmar que as TIC são o alicerce da transformação digital da economia atual, com base no entendimento de que o indivíduo instrumentalizado estará mais apto a ir em busca de seus direitos, rompendo com as limitações impostas pela sociedade.

De Bustos (2007) diz que não acessar as redes significa estar fora do mundo das finanças, das comunicações, do comércio eletrônico etc., o que é o mesmo de estar mais à margem do que antes. Por meio das redes, pode se ter acesso a todos os recursos do saber científico, a fim de que qualquer universidade africana possa acessar os mesmos recursos que uma universidade norte-americana.

Nessa perspectiva, as TIC ampliam o desenvolvimento à medida que se configuram como instrumentos que propiciam o acompanhamento do avanço tecnológico e auxiliam o cidadão na busca de seus mais diversos direitos, pois aquilo que as pessoas conseguem realizar é influenciado por oportunidades econômicas, liberdades políticas, poderes sociais e por condições habilitadoras, tais como boa saúde, educação básica e incentivo e aperfeiçoamento de iniciativas (SEN, 2010).

Considerando, pois, que as TIC impactam na vida das pessoas, a pesquisadora Dorothea Kleine tratou dessa temática na obra intitulada Tecnologias de escolha - TICs, desenvolvimento e abordagem de capacidades, na qual traduz a abordagem das capacidades (ou de liberdades) de Amartya Sen. A nova leitura sobre desenvolvimento contempla a pluralidade das pessoas e da vida que elas querem viver, possibilitando que elas façam escolhas nas esferas pessoal, social, política, cultural e econômica.

A autora defende que o desenvolvimento está intrinsecamente ligado às TIC, uma vez que estas desempenham um papel fundamental nas mudanças e na maneira como as pessoas vivem. À medida que o desenvolvimento tem a ver com a mudança, não é de surpreender que as TIC 
tenham chamado a atenção de estudiosos e profisssionais que trabalham no desenvolvimento (KLEINE, 2013).

Buscando comprovar que o desenvolvimento é o fim e as TIC são os meios para alcançá-lo, a pesquisadora realizou um estudo de caso em uma cidade do Chile, primeiro país da América do Sul a traçar uma estratégia nacional com o uso das TIC. A esse caso exitoso, atribuiu-se a modernização tecnológica e o investimento em uma força de trabalho qualificada.

No Brasil, o Comitê Gestor da Internet e o Núcleo de Informação e Coordenação do Ponto BR, por meio do Centro Regional de Estudos para o Desenvolvimento da Sociedade da Informação (CETIC), realizam estudos com vistas a fornecer subsídios para a elaboração de políticas públicas e pesquisas de cunho acadêmico e científico. O referido Comitê conta com o apoio da UNESCO.

Assim, as pesquisas realizadas pelo CETIC possibilitam o acompanhamento das mudanças ocorridas no país ao longo dos anos e de como as TIC impactam na rotina dos brasileiros. Ainda, servem como subsídio aos governantes no sentido de utilizarem esses dados como forma estratégica para implementar políticas públicas que possibilitem o acesso dos cidadãos a tais tecnologias.

O Comitê Gestor de Internet realizou, no ano de 2017, a pesquisa TIC Domicílios para mapear o acesso a essas tecnologias por parte dos domicílios brasileiros. A pesquisa revelou que a área urbana concentra maior usabilidade de TIC em detrimento da área rural; que a região sudeste se destaca quanto ao uso das TIC, enquanto a região norte amarga a última posição; e, ainda, que a renda familiar tem influência sobre o uso das tecnologias.

Os dados evidenciam que há grandes disparidades quanto à usabilidade das TIC e, consequentemente, do acesso à informação. É necessária a implementação de políticas públicas que venham promover a igualdade e vislumbrar nas TIC um caminho para o desenvolvimento, a exemplo da experiência exitosa do Chile. Dotar os munícipes de informações e tecnologias, com vistas a combater as restrições impostas pela sociedade, e instrumentalizá-los por meio de telecentros são passos importantes para o alcance desse objetivo. Criar marcos regulatórios que, verdadeiramente, promovam uma interação entre o Estado e o cidadão também é de salutar importância neste processo.

\subsection{Comunicação pública}

De acordo com estudiosos da área de comunicação pública, esta ainda possui uma definição polissêmica. Alguns autores a tratam como uma vertente da comunicação política que se faz presente por meio de um conjunto de técnicas utilizadas por políticos visando persuadir e manipular a opinião pública. Entretanto o presente estudo abordou a comunicação pública como aquela que provê a sociedade civil organizada de informações de interesse público e que estimula a reflexão e o debate público. Duarte (2007) diz que a comunicação pública deve incluir a possibilidade de o cidadão ter pleno conhecimento da informação que lhe diz respeito, inclusive aquela que não busca por não saber que existe.

Zémor (2009) enfatiza essa linha teórica quando diz que se espera da comunicação pública que sua prática contribua para alimentar o conhecimento cívico, facilitar a ação pública e garantir o debate público. Implica dizer que as informações públicas produzidas pelo Estado ou que estão sob sua custódia poderão ser disponibilizadas ao cidadão como um direito assegurado.

Santos, Carniello e Oliveira (2013) afirmam que o cenário midiático contemporâneo é ambiente propício para a disponibilização de informações à sociedade e para o diálogo mais 
próximo entre governo e cidadão. Nesse processo, a inovação tecnológica se faz presente, considerando que a comunicação pública se realiza por meio das TIC, que contribuem para fortalecer o diálogo do cidadão com a administração pública local, o que tende a diminuir o abismo existente entre sociedade e Estado, tendo como resultado a prática da cidadania.

Em tempos de midiatização, observa-se que a administração pública, de uma forma geral, tem também buscado acompanhar cada vez mais essas mudanças, conforme será abordado a seguir.

\subsection{As TIC na administração pública}

É notório que a administração pública vem procurando adaptar-se às mudanças tecnológicas como forma de se adequar a essa nova realidade que exige do serviço público boas práticas que vão impactar de forma positiva nos padrões de relacionamento do governo com os cidadãos.

Brito $(2006$, p. 112) diz que "[...] a presença e a importância das TIC nos órgãos governamentais contribuem para mudanças que propiciam o surgimento de um conceito funcional de sistema misto de governo tradicional e governo eletrônico."

Nesse sentido, é possível identificar no âmbito da administração pública, por exemplo, diversas transformações que envolvem o uso das TIC, tendo em vista o aprimoramento da gestão, tais como o Portal da Transparência, para conhecimento dos gastos do governo federal; o registro de boletins de ocorrência de forma on-line, de responsabilidade das Secretarias de Segurança Pública dos estados; a utilização de "computadores de mão" por parte do Instituto Brasileiro de Geografia e Estatística (IBGE) para fins de censo populacional; o sistema Receitanet, da Secretaria da Receita Federal, que permite a entrega da declaração do imposto de renda via internet.

Trata-se de uma inovação na prestação de serviços públicos, denominada de governo eletrônico ou e-gov, que, como o próprio nome sugere, está relacionado com a oferta de serviços governamentais em formato eletrônico, utilizando-se das TIC. Na visão de Neto, Fisher e Gouvea (2004), o e-gov trata-se de um governo ágil e aberto para melhor atender à sociedade, utilizando-se de tecnologias, visando ampliar a cidadania, aumentar a transparência da gestão pública, facilitar o controle popular do poder público e democratizar o acesso do cidadão aos meios eletrônicos.

Destaque-se, ainda, que o Brasil necessita avançar nas políticas de inclusão digital. Assim, a eficácia da ação governamental está estritamente ligada "[...] a participação da sociedade civil e da articulação de atores sociais para as ações voltadas para o desenvolvimento, seja em escala nacional, regional ou local" (BANDEIRA, 1999, p. 10).

O aprofundamento do debate sobre as contribuições da comunicação para o desenvolvimento, em particular com os recursos digitais, é algo inovador para o cenário atual, com vistas à elevação da transparência, da participação social e, ainda, o empoderamento do cidadão em razão das novas possibilidades de comunicação.

Um outro mecanismo para mediar a participação social é o Serviço Eletrônico de Informação ao Cidadão (e-SIC). Trata-se de um sistema que visa efetivar o direito de acesso à informação no Brasil, instituído por meio da Constituição Federal de 1988. Um direito que inclui a liberdade de, sem interferência, ter opiniões e de procurar, receber e transmitir informações e ideias por quaisquer meios e independentemente de fronteiras (ORGANIZAÇÃO DAS NAÇÕES UNIDAS [ONU], 1948). 
A Lei de Acesso à Informação (LAI) foi instituída no Brasil em 18 de novembro de 2011 (BRASIL, 2011) e regulamentada pelo Decreto n. 7.724/2012 (BRASIL, 2012). Um importante mecanismo de participação popular, tendo em vista a governança institucional, por meio do acompanhamento das ações governamentais, tais como: dados sobre a execução de projetos, obras e demais gastos do governo; perguntas relacionadas à saúde, educação e cultura - alguns dos itens que a população manifesta interesse em ter conhecimento das informações.

Escaleras (2010, p. 135) aponta que o acesso à informação pública, além de um direito fundamental, é uma importante ferramenta para o combate à corrupção e para o fortalecimento do processo democrático. Partindo, pois, do princípio de que todo cidadão bem informado está mais apto a conhecer e buscar outros direitos fundamentais, como educação, saúde, segurança, faz-se necessário o estímulo cada vez mais cedo a essa busca pela informação, visando à formação de cidadãos críticos e que participam do processo de tomada de decisão do poder público.

O direito de acesso à informação também é garantido quando há a publicação de informações de forma ativa, sem a necessidade de requerimentos, nos sites oficiais dos órgãos públicos. Conhecida também como transparência ativa, trata-se de uma exigência do Decreto $\mathrm{n}$. 7.724/2012 (BRASIL, 2012), tendo em vista disponibilizar informações relacionadas à estrutura organizacional, programas e projetos, licitações, execução orçamentária e financeira. Disponibilizar informações que são de interesse público é premissa para uma sociedade mais democrática e participativa.

\section{MÉTODO}

Esta pesquisa caracteriza-se como exploratório-descritiva, de abordagem qualitativa e quantitativa, realizada no Município de São Luís, MA. A discussão teve como suporte teórico o debate sobre comunicação pública - compreendida na pesquisa como aquela que provê o cidadão de informações de interesse público e o desenvolvimento multidimensional, proposto por Kleine, marco teórico do estudo, que defende que o paradigma dominante do desenvolvimento pelo viés econômico é muito limitante para entender todo o potencial dessas tecnologias (KLEINE, 2013). Ela propõe uma estrutura conceitual inovadora (Figura 1), do ponto de vista do desenvolvimento humano, "O Quadro de Escolha", que pode ser usado para analisar o papel das TIC nos processos de desenvolvimento, cuja estrutura consolidou-se como método da pesquisa. 
Figura 1- O quadro de escolha

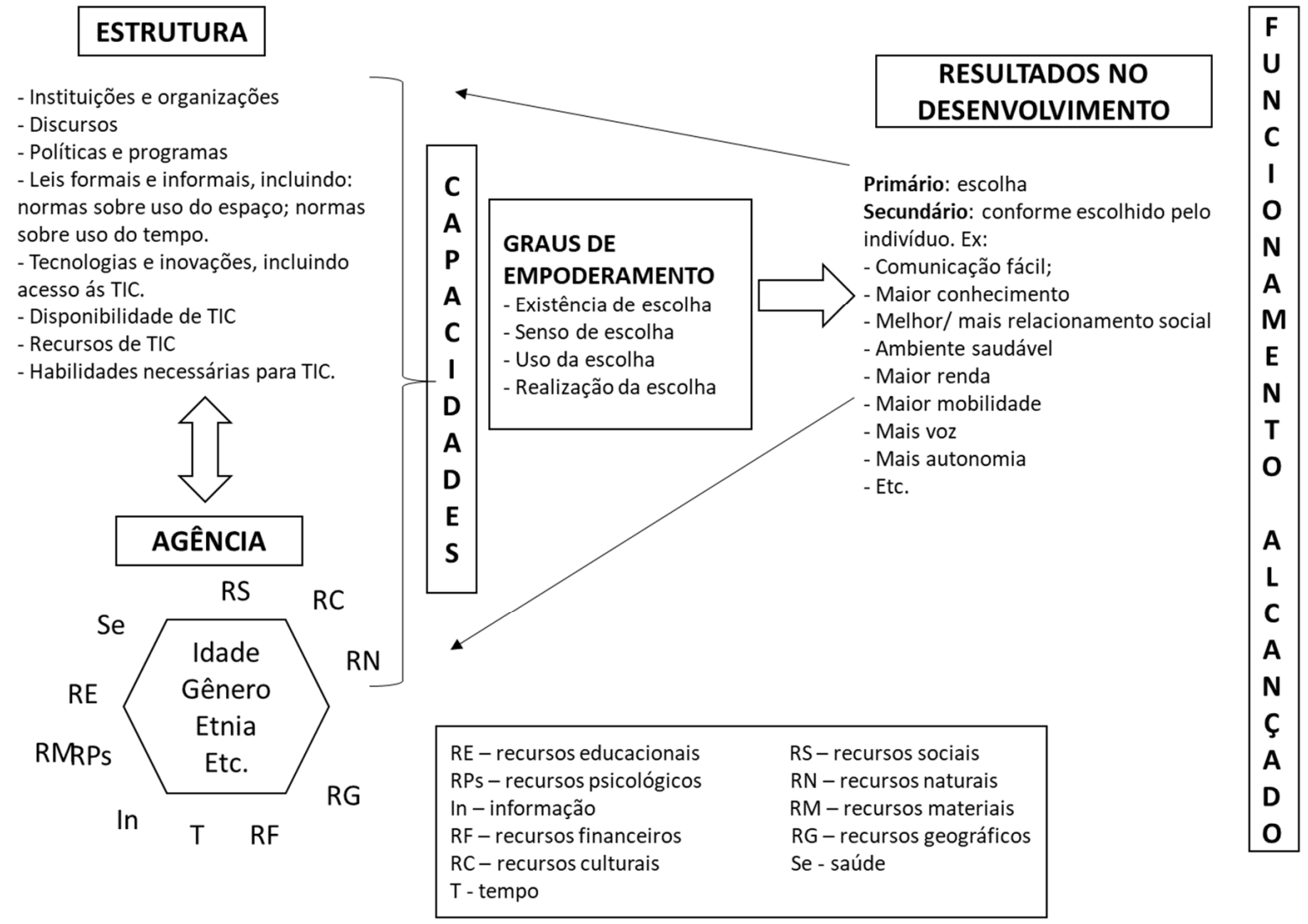

Fonte: Adaptado de Kleine (2013)

A autora apresenta por meio do "Quadro de escolha" o desenvolvimento de uma maneira multidimensional, em concordância com a abordagem de Sen (2000) sobre as capacidades ou liberdades individuais no campo da comunicação para o desenvolvimento.

A pesquisa teve como participantes, respectivamente, os gestores municipais, ocupantes de cargos estratégicos e os moradores do município, representantes de diversos segmentos, tais como profissionais da saúde, do comércio, da indústria, estudantes e servidores públicos.

A primeira fase, de abordagem qualitativa, consistiu em aplicação de entrevista a representante da Secretaria de Informação e Comunicação do Município e representante da Controladoria do Município.

A segunda fase, de abordagem quantitativa, obteve uma amostra de 384 entrevistados, considerando população de 1.094 .667 pessoas (IBGE, 2018), com nível de confiança de 95\% e margem de erro de $5 \%$.

Os instrumentos de coleta de dados foram elaborados especificamente para a pesquisa, fundamentados no Quadro de Escolha de Kleine (2013) (Figura 1) e validados por um Comitê de Ética em Pesquisa. A coleta de dados foi realizada no primeiro semestre de 2019.

\section{ACESSO À INFORMAÇÃO EM SÃO LUÍS, MA, NA PERCEPÇÃO DOS MUNÍCIPES}

Apresentam-se a seguir os resultados da pesquisa quantitativa, que contemplou a aplicação de 384 (trezentos e oitenta e quatro) questionários aos munícipes de São Luís, MA, com 
representantes da zona urbana e rural. Na análise sociodemográfica, teve-se como resultado: $56,3 \%$ dos entrevistados foram do sexo feminino e $43,8 \%$ do sexo masculino; a maioria dos entrevistados compreendeu a faixa etária de 25 a 35 anos (30,2\%); quanto à escolaridade, 27,9\% dos munícipes disseram ter o ensino médio completo e 50,5\% disseram residir no município há mais de 21 anos; em relação ao local, 92,2\% disseram morar na área urbana de São Luís, MA, e $7,8 \%$ na área rural.

Quanto ao número de pessoas que moram na residência, os entrevistados afirmaram que é de 3 a 4 pessoas. Em relação à renda familiar, disseram ter um rendimento nominal mensal entre 2 e 5 salários mínimos. Sobre a atividade profissional, a pesquisa revelou que 20,1\% dos entrevistados disseram não ter atividade remunerada, seguidos daqueles que disseram atuar no comércio $(19,5 \%)$ e, ainda, dos entrevistados que disseram desenvolver atividade profissional no serviço público $(15,1 \%)$.

Gráfico 1 - Acesso à internet

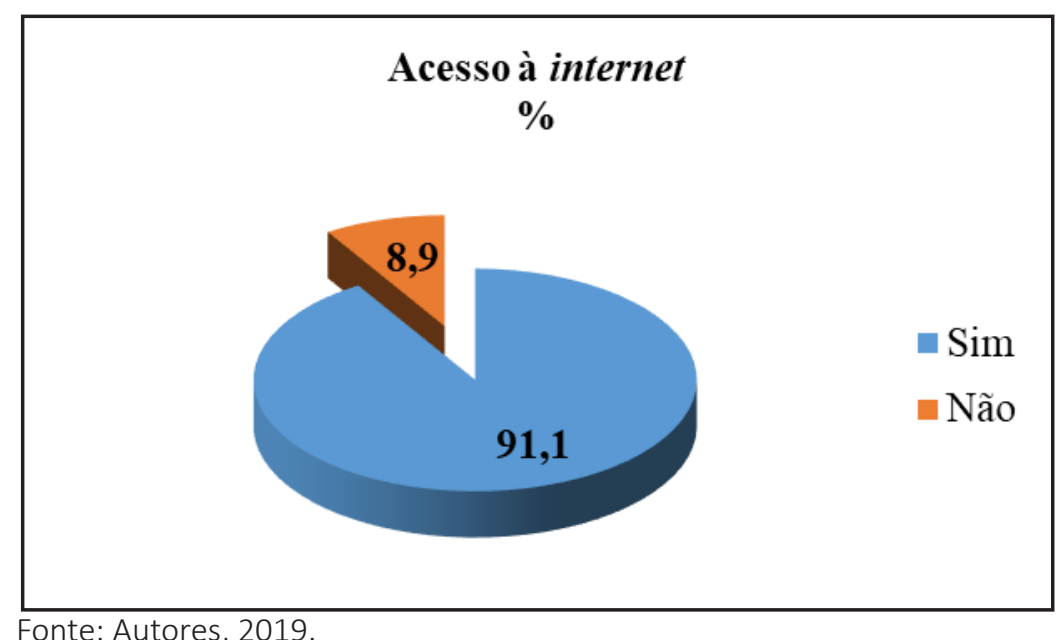

Em relação às condições e caracterização de acesso à internet, perguntou-se aos entrevistados se eles tinham acesso em São Luís, MA. O resultado evidenciou a expressividade de acesso à internet no referido município, que é de 91,1\%, conforme Gráfico 1. Tal constatação coaduna com a Pesquisa TIC domicílios 2017, que demonstrou que a proporção de domicílios com acesso à internet é ascendente ao longo dos anos. 
Gráfico 2 - Local de acesso à internet

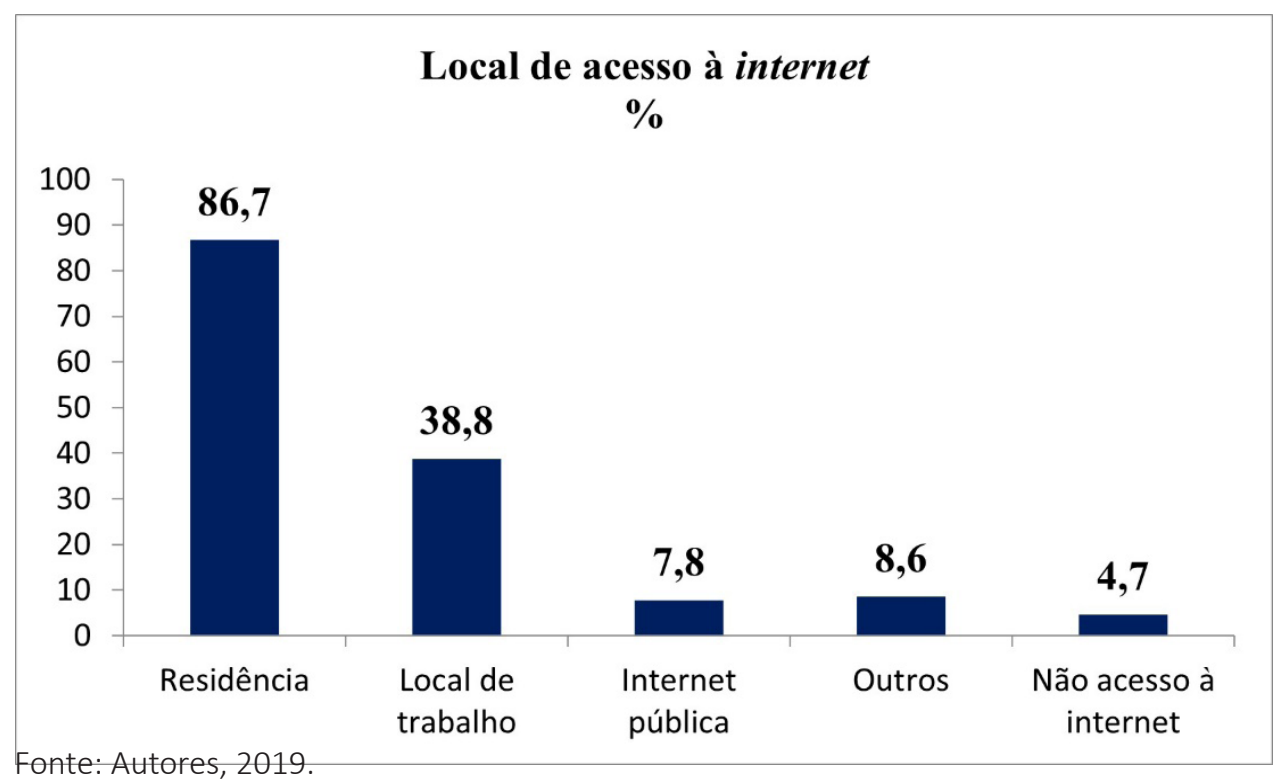

Quanto ao local de acesso à internet, o Gráfico 2 revelou que 86,7\% dos entrevistados disseram acessar a internet da própria residência. Conforme dados do Instituto Brasileiro de Geografia e Estatística (2018), a população de São Luís encontra-se em sua maioria na zona urbana, e esta concentra maior usabilidade de TIC em detrimento da área rural, pouco servida dessas tecnologias; logo, o indivíduo que mora na zona rural de São Luís, MA, teria maiores restrições de acesso às informações públicas, visto que o serviço de internet, por muitas vezes, não chega a esses locais.

Gráfico 3 - Possuem celular smartphone

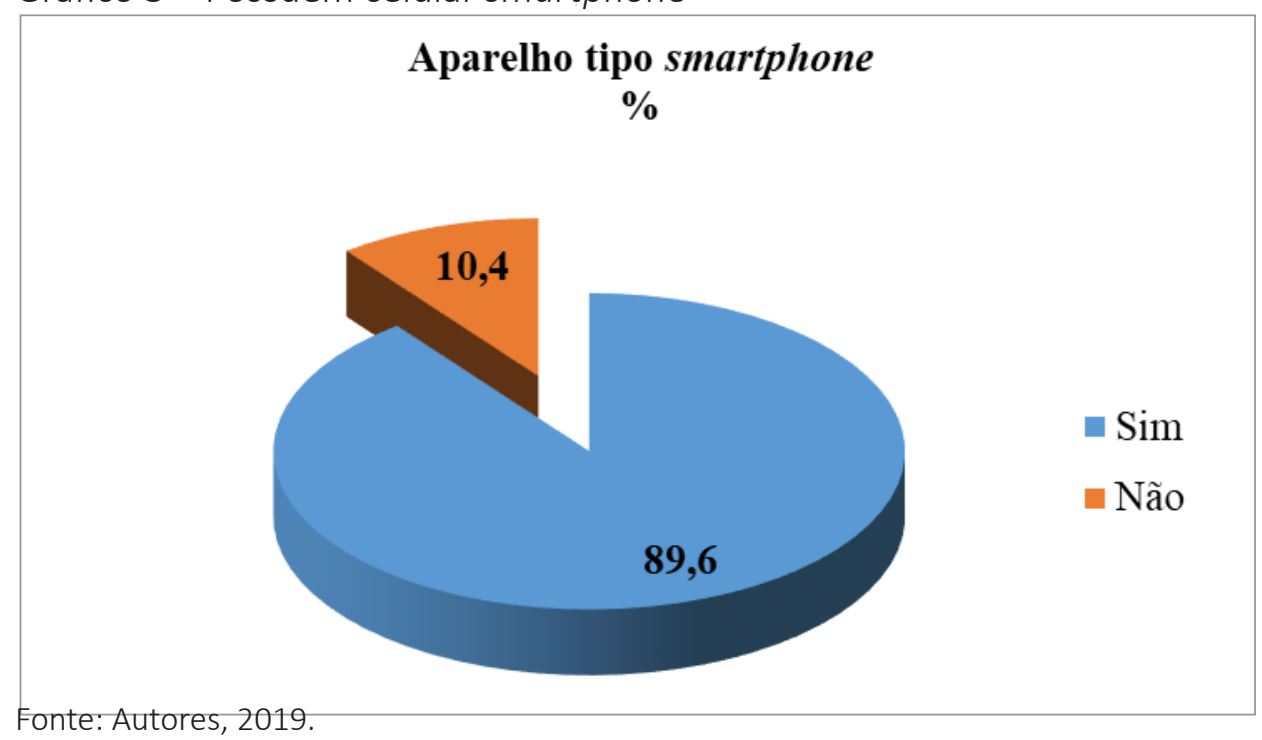

Os resultados da pesquisa constataram que quase $90 \%$ (noventa por cento) dos entrevistados disseram ter aparelho celular do tipo smartphone, segundo o Gráfico 3. Esse resultado coaduna com a pesquisa TIC Domicílio do Comitê Gestor de Internet (COMITÊ GESTOR DA INTERNET NO BRASIL [CGI], 2017), relacionada a domicílios que possuem equipamento TIC. No rol de 
equipamentos apresentados, o aparelho celular encontra-se em segundo lugar, perdendo apenas para a televisão.

Gráfico $4-\mathrm{O}$ acesso à internet e o atendimento de necessidades

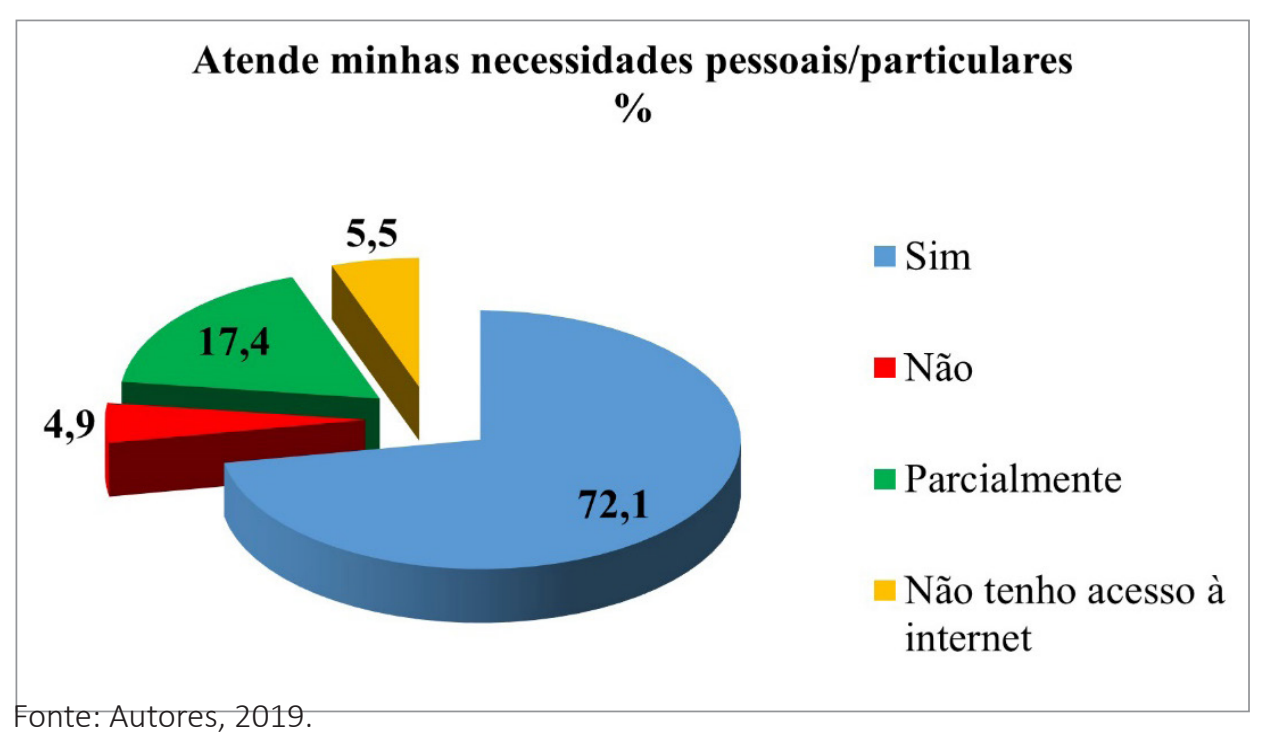

De acordo com o Gráfico 4, para um grupo de quase 73\% dos respondentes da pesquisa, o acesso à internet atende a suas necessidades pessoais/particulares. Isso demonstra que um número cada vez maior se utiliza dos equipamentos tecnológicos, uma vez que "[...] a evolução da tecnologia determinou em grande parte a capacidade produtiva da sociedade e os padrões de vida" (CASTELLS, 2017, p. 119).

Gráfico 5 - Uso da internet e suas finalidades

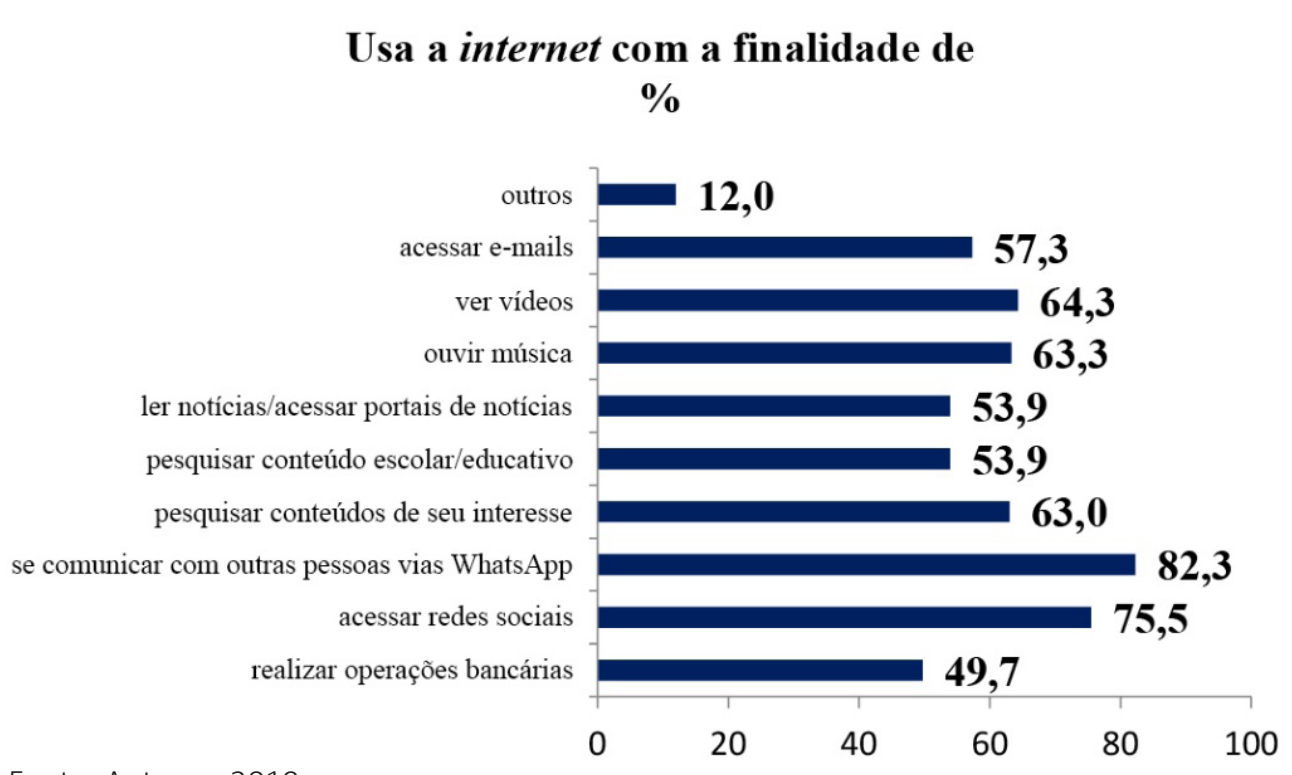

Fonte: Autores, 2019.

O Gráfico 5 apresenta o resultado da seguinte pergunta feita aos munícipes: "Indique 
para quais finalidades pessoais/particulares você faz uso da internet". Cerca de 82,3\% dos entrevistados responderam que utilizam a internet para comunicar-se com outras pessoas via WhatsApp; 75,5\% disseram para acessar as redes sociais; outros $64,3 \%$ para ver vídeos; $63,3 \%$ para ouvir música; e 63\% para pesquisar conteúdos de seu interesse. Os resultados demonstram que as pessoas dedicam um tempo maior ao entretenimento que a internet proporciona, cujo fenômeno é explicado por Lopes (2011) quando diz que o advento da tecnologia trouxe novas formas e possibilidades de sociabilidade.

Gráfico 6 - Existência de canais para manifestação

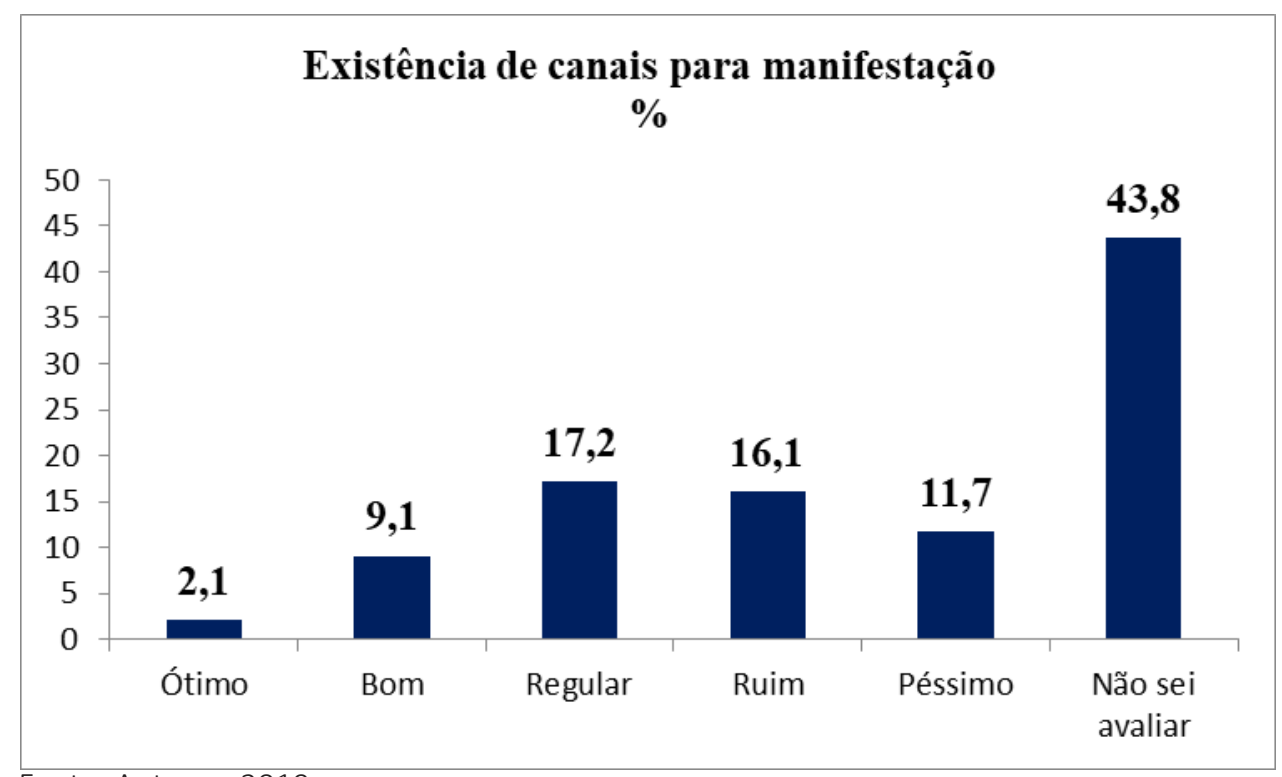

Fonte: Autores, 2019.

Sobre a existência de canais para o cidadão manifestar-se, os resultados demonstraram que $43,8 \%$ dos entrevistados disseram não saber avaliar, 17,2\% consideraram "regular", 16,1\% externaram ser "ruim" e 11,7\% avaliaram como "péssimo". Dos demais entrevistados, 9,1\% disseram ser "bom" e 2,1\% avaliaram como "ótimo" os canais disponibilizados pela gestão, de acordo com o Gráfico 6.

Ressalte-se que o Munícipio de São Luís, MA, tem instituído canais para manifestação do usuário de serviço público, tais como sistema de ouvidoria (e-OUV), para abertura de demandas relacionadas à insatisfação quanto à oferta de um serviço público, sugestão para melhoria dos serviços existentes ou ainda envio de denúncias de irregularidades ocorridas na administração. Todos os canais citados são acessíveis por TIC. 
Gráfico 7 - Oferta de cursos básicos de informática

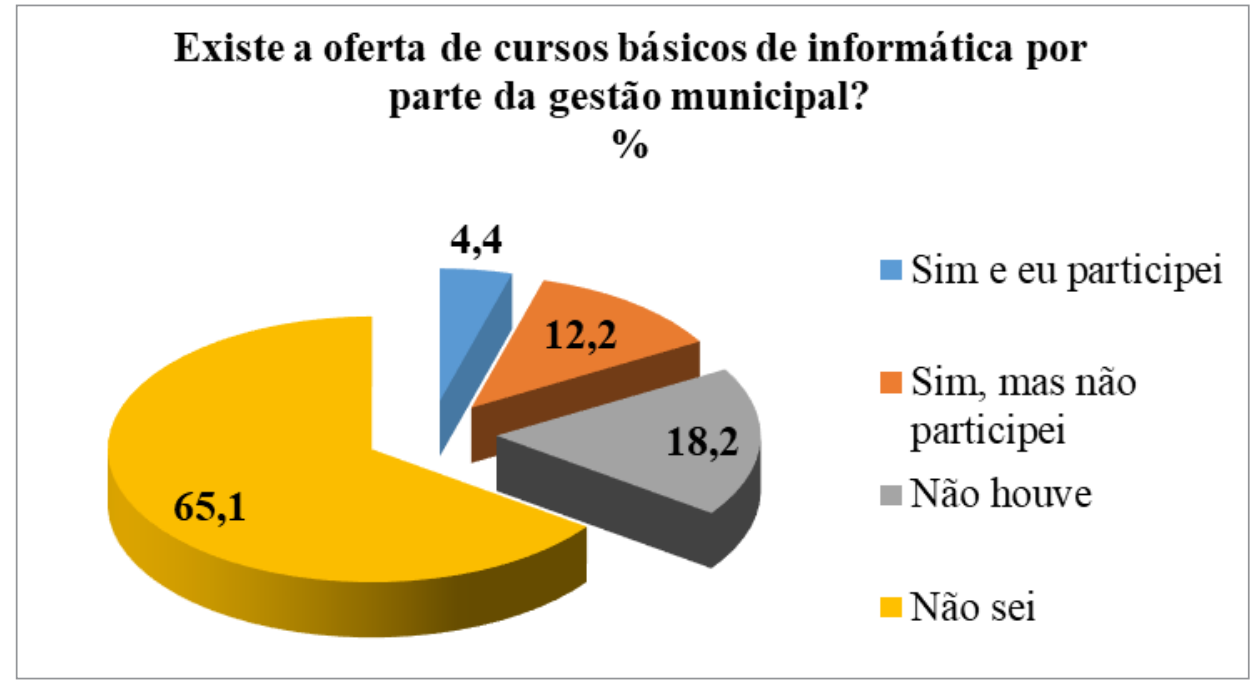

Fonte: Autores, 2019.

Quando perguntado aos entrevistados se existe a oferta de cursos básicos de informática por parte da gestão municipal, 65,1\% disseram não saber da oferta, 18,2\% afirmaram que não houve a existência desses cursos, outros 12,2\% disseram saber da oferta, mas não participaram, e 4,4\% dos entrevistados expuseram que sabem e que participaram de cursos básicos de informática ofertados pela Prefeitura Municipal de São Luís, MA, de acordo com o Gráfico 7.

Este resultado evidencia, sobretudo, a ausência de políticas educacionais, tão necessárias para a formação de um cidadão crítico, ciente de seus direitos e deveres, considerando que a educação também é uma vertente para o desenvolvimento.

Gráfico 8 - Utilização do Sistema e-SIC adotado pelo Município

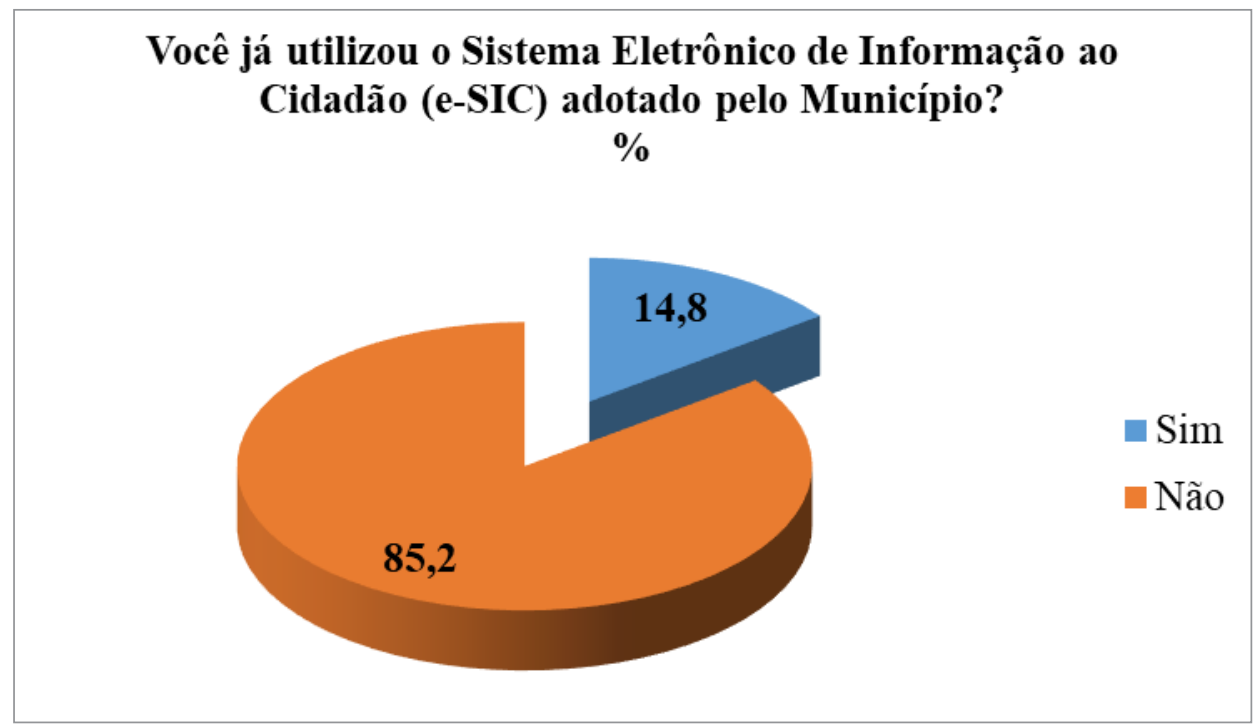

Fonte: Autores, 2019.

O Gráfico 8 apresenta o resultado da seguinte pergunta: você já utilizou o Sistema Eletrônico de Informação ao Cidadão adotado pelo Município? Dos entrevistados, 85,2\% disseram não ter 
utilizado o e-SIC, enquanto 14,8\% disseram que já fizeram uso do referido sistema. Ao analisar o resultado desta pergunta, constata-se que ainda é bastante tímida a utilização do referido sistema por parte da população, uma evidência de que os munícipes desconhecem o que é, de fato, disponibilizado pelo e-SIC.

\section{Gráfico 9 - Acompanhamento das ações da Gestão Municipal}

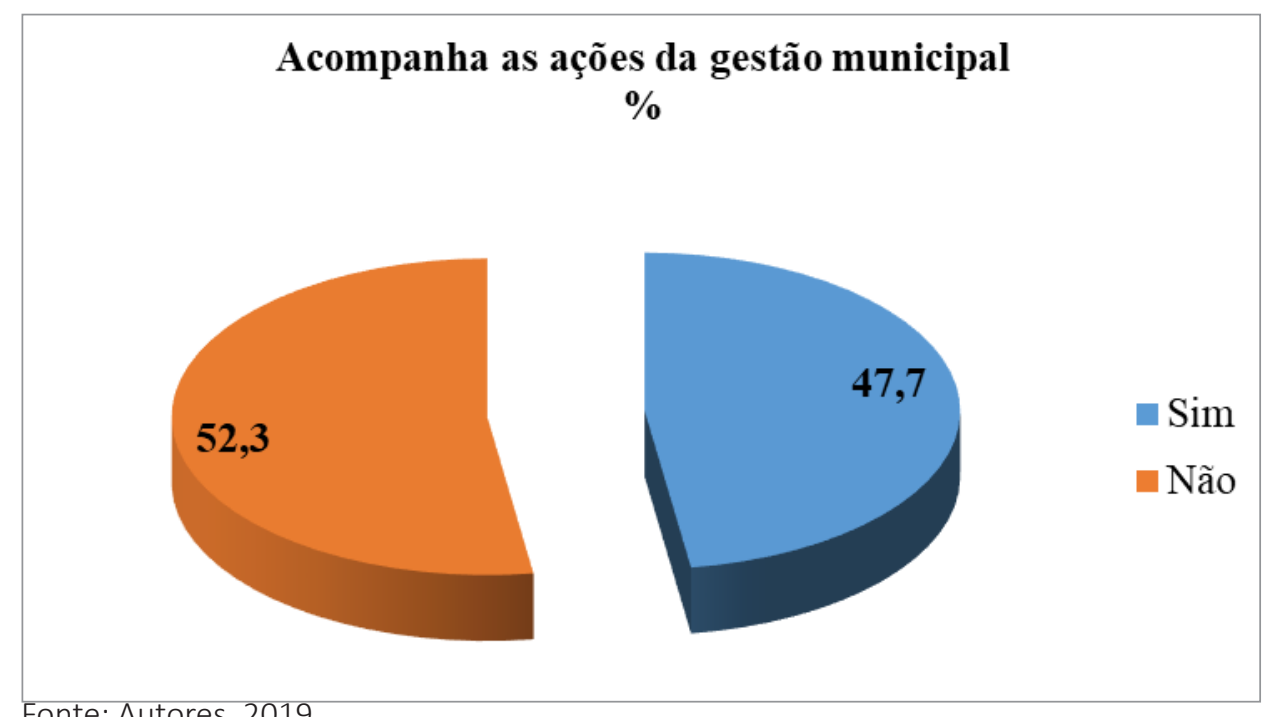

Fonte: Autores, 2019.

Quando perguntado aos munícipes de São Luís, MA, se eles acompanham as ações da gestão municipal, 52,3\% dos entrevistados disseram que não acompanham e 47,7\% disseram que acompanham, conforme Gráfico 9. Nesse quesito, cabe destacar as contribuições de Bourdin (2001): é impossível definir fronteiras entre o regional, o local e o comunitário. Entretanto, em tempos de globalização, valoriza o local como uma "[...] forma que constitui um nível de interação das ações dos atores, dos grupos e das trocas. Essa forma é caracterizada com uma relação com o lugar, que varia em sua intensidade e em seu conteúdo." (BOURDIN, 2001, p. 56). Nesse sentido de troca e interação, é fundamental que as ações da gestão municipal sejam pautadas na democracia, no diálogo com os munícipes (audiências públicas, por exemplo) para o devido acompanhamento das políticas públicas por parte do cidadão. 
Gráfico 10 - Avaliação dos entrevistados sobre o uso das TIC

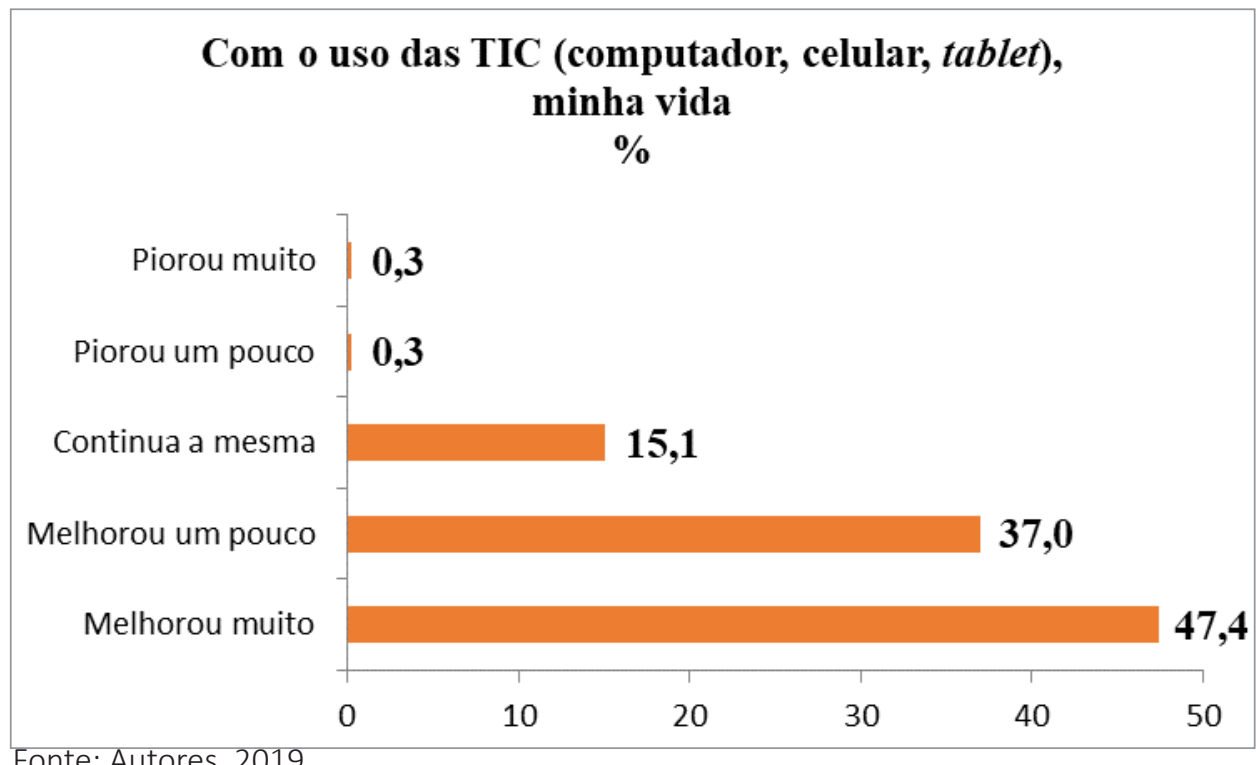

Um número considerável de entrevistados, cerca de 47,4\%, afirmou que, no momento que passou a utilizar as TIC, a vida melhorou muito. Outros $37 \%$ disseram que melhorou um pouco, e 15,1\% manifestaram-se dizendo que a vida continua a mesma. Apontam-se, ainda, os respondentes que disseram que a vida piorou muito e os que disseram que a vida piorou um pouco, ambos com $0,3 \%$.

Cabe destacar que os munícipes que disseram que a vida melhorou atribuíram como ponto positivo a melhoria na comunicação promovida pelo uso de aplicativos, tais como o WhatsApp, o acesso a serviços bancários e, ainda, a busca de conhecimento a partir de cursos da modalidade EAD. A respeito dessas melhorias evidenciadas com o progresso tecnológico, Pieniz e Silveira argumentam:

Tecnologias de informação e comunicação móveis, equipamentos portáteis e a internet permitem o desenvolvimento de uma computação que se denomina pervasiva, com mobilidade e acesso global aos recursos computacionais pelo usuário. Potencializar o imbricamento das TIC através de linguagens que historicamente se desenvolveram por processos distintos é o desafio das novas gerações. (PIENIZ; SILVEIRA, 2011, p. 242).

Portanto, cada vez mais, as TIC e a internet são responsáveis pela construção de uma sociedade em rede, marcada por uma comunicação instantânea e interativa, sobretudo centrada no usuário, promovendo mudanças positivas na vida das pessoas.

\section{ACESSO À INFORMAÇÃO EM SÃO LUÍS, MA, NA PERCEPÇÃO DOS GESTORES}

Com o objetivo de compreender melhor sobre o acesso à informação no Município de São Luís, MA, foram realizadas entrevistas do tipo semiestruturada junto aos gestores municipais, a saber: o secretário municipal de Informação e Tecnologia, responsável pelas informações publicadas no site oficial do município, e o chefe da Controladoria-Geral do Município, responsável pelo tratamento dos pedidos de informação.

As entrevistas foram realizadas com vistas a identificar a relação comunicação e 
desenvolvimento, bem como analisar as falas externadas pelos entrevistados em conformidade com o "Quadro de Escolha" proposto por Kleine (2013). Posteriormente, utilizou-se a análise de conteúdo para tratar os dados coletados nas entrevistas.

Quanto à "estrutura", observou-se que há, nas falas dos gestores do Município de São Luís, MA, uma preocupação em relação à disseminação do uso das TIC, consideradas por eles como peças necessárias para a busca do acesso à informação. No entanto as entrevistas constataram que não há políticas e/ou programas que fomentem a inclusão digital, o que fragiliza o processo de democratização das informações públicas.

Em relação à agência, os entrevistados disseram que a gestão disponibiliza canais para interação com o cidadão. Por outro lado, faz-se necessária uma ampla divulgação dos canais à população, bem como ações que venham dotar o munícipe de habilidades para utilização destes. Desse modo, constatou-se o isolamento da gestão municipal, com foco apenas no cumprimento de obrigações impostas pelas legislações vigentes, mas que não planeja ações que visem ampliar as capacidades dos munícipes, tais como a oferta de cursos de informática e a implementação de telecentros.

Em relação aos graus de empoderamento, constatou-se que os representantes da gestão exemplificaram que o Município apresentou inovações na oferta de serviços, acessíveis por TIC, como o cadastro habitacional e o geoprocessamento. Ressalte-se que a melhoria do serviço público prestado se configura também como fator de desenvolvimento, todavia a inovação de um serviço público deve ser de conhecimento da população.

Em relação aos "resultados do desenvolvimento", ambos os entrevistados afirmaram que as TIC são ferramentas que viabilizam um melhor controle social dos atos governamentais. De fato, com o advento das TIC, busca-se cada vez mais uma maior aproximação entre governo e sociedade, ampliando os espaços na esfera pública e as possibilidades para o cidadão.

Segundo Castells (2003), o uso da internet amplia a sociabilidade, tanto à distância quanto na comunidade local, para fins instrumentais ou emocionais, e para a participação social na comunidade. Diante disso, a transparência das informações é prerrogativa para que ocorram processos democráticos e de acompanhamento da gestão.

Para tanto, a existência de marcos regulatórios que determinem e garantam a efetividade de direitos é de extrema importância, a exemplo do Decreto n. 7.724/2012 (BRASIL, 2012), que regulamentou a LAI no âmbito federal, que trata dos mecanismos de transparência ativa, especificamente no artigo 70 e seu parágrafo 3ㅇ.

Desse modo, em relação aos mecanismos de transparência ativa verificados no site oficial do Município, constatou-se que o Município torna público conteúdos relacionados à gestão municipal, porém com algumas ressalvas. Em uma avaliação geral, o site disponibiliza informações úteis aos munícipes, aos servidores, aos empresários e aos turistas.

Importante mencionar que o site oficial do Município apresenta subportais, que contemplam as diversas Secretarias da gestão, e seus respectivos conteúdos, tais como: Secretaria Municipal da Criança e da Assistência Social, Secretaria Municipal de Administração, Secretaria Municipal de Educação, assim por diante. 


\section{CONSIDERAÇÕES FINAIS}

Sabe-se que a educação para a cidadania é o primeiro passo para a construção de uma sociedade pautada nos valores de igualdade e justiça social, contribuindo para formação de pessoas autônomas, democráticas, sabedoras de seus direitos e deveres, as quais buscam dialogar sobre os problemas que afetam a coletividade. Os resultados da pesquisa mostraram que a maioria das pessoas não acompanha as ações governamentais no Município de São Luís, MA, bem como não soube avaliar os canais disponibilizados pelo Município para esse fim. Isso demonstra claramente que um número considerável da população não foi educado para refletir sobre as diversas dimensões da educação para a cidadania, entre elas, o acesso à informação.

A pesquisa constatou, ainda, que o problema não está no acesso à informação, uma vez que os munícipes possuem TIC com acesso à internet, e a gestão municipal disponibiliza canais para contato, tais como o e-SIC e sistema de ouvidoria. Ocorre que a população pouco tem demandado a gestão por meio desses canais - fato este que pode ter diversas motivações, entre elas, a pouca confiabilidade nos canais, ou ainda, que o cidadão busque essa participação política por meio de redes informais, fora do ambiente governamental.

A comunicação pública instituída na gestão municipal ainda está no status informacional, uma vez que não há incentivo para a participação popular no âmbito da administração municipal, bem como a ausência de políticas com o objetivo de discutir temas tão necessários para os dias atuais, como cidadania e democracia.

Observou-se, nas entrevistas realizadas com os gestores, que a perspectiva do governo é difusionista, uma vez que eles atribuem a pouca procura dos canais aos cidadãos ludovicenses, acreditando que disponibilizar o site oficial e sistemas para contato com a gestão é o suficiente para gerar a comunicação.

Ficou evidente, ainda, que os discursos políticos são no sentido de ampliação das capacidades dos munícipes, mas que a realidade não corresponde à fala por eles reproduzidas, visto que não existem políticas ou programas que capacitem o cidadão para o uso das TIC, bem como não há políticas educacionais de formação para a cidadania.

Entende-se que o acesso à informação é condição essencial para a ampliação das capacidades e que tal acesso está intrinsicamente ligado, na era atual, à apropriação das tecnologias de informação e comunicação. Estas representam uma possibilidade do direito à informação nunca antes visto. Para tanto, é urgente a promoção de ações no âmbito do Município de São Luís tendo em vista a inclusão digital, que perpasse o acesso às TIC, e, sobretudo, que as pessoas tenham autonomia para resolver suas demandas, sejam elas de ordem pessoal ou coletiva, por intermédio dessas tecnologias.

\section{REFERÊNCIAS}

BANDEIRA, P. Participação, articulação, de atores sociais e desenvolvimento regional. Brasília: IPEA, 1999. (Texto para Discussão, n. 630).

BOURDIN, A. A questão local. Rio de Janeiro: DP\&A, 2001.

BRASIL. Decreto 7.724, de 16 de maio 2012. Regulamenta a Lei n. 12.527, de 18 de novembro de 2011, que dispõe sobre o acesso a informações previsto no inciso XXXIII do caput do art. 5, no inciso II do $\S 3$ o do art. 37 e no § 2ㅇ do art. 216 da Constituição. Diário Oficial da República Federativa do Brasil, Brasília-DF, nov. 2012. 
BRASIL. Lei n. 12.527, de 18 de novembro de 2011. Regula o acesso a informações previsto no inciso XXXIII do art. 5으, no inciso II do § $3 \circ$ do art. 37 e no $\S 2$ o do art. 216 da Constituição Federal; altera a Lei n. 8.112, de 11 de dezembro de 1990; revoga a Lei n. 11.111, de 5 de maio de 2005, e dispositivos da Lei n. 8.159, de 8 de janeiro de 1991; e dá outras providências. Diário Oficial da República Federativa do Brasil, Brasília-DF, 18 nov. 2011.

BRITO, J. A. P. Cibercidadania: a virtualização na comunicação pública contemporânea. Organicom - Revista Brasileira de Comunicação Organizacional e Relações Públicas, São Paulo, v. 3, n. 4, p. 106-23, 2006. Disponível em: $h$ ttp://www.eca.usp.br/departam/crp/cursos/posgrad/gestcorp/organicom/re_vista4/106. pdf. Acesso em: 20 out. 2019.

CASTELLS, M. O Poder da Comunicação. Rio de Janeiro: Paz \& Terra, 2017.

COMITÊ GESTOR DA INTERNET NO BRASIL [CGI]. Pesquisa sobre o uso das Tecnologias de Informação e Comunicação nos Domicílios Brasileiros: TIC Domicílios 2017. São Paulo: CGI; NIC; CETIC, 2018.

DE BUSTOS, J. M. Comunicación sostenible y desarrollo humano en la sociedad de la información. Madrid, España: $\mathrm{AECl}, 2007$.

DUARTE, J. Instrumento de comunicação pública. In: DUARTE, Jorge (Org.). Comunicação pública: estado, mercado, sociedade e interesse público. São Paulo: Atlas, 2007.

ESCALERAS, M.; LIN, S.; REGISTER, C. Freedom of information acts and public sector corruption. Public Choice, Leiden, v. 145, n. 3, p. 435-60, 2010.

FURTADO, C. Teoria e política do desenvolvimento econômico. São Paulo: Victor Civita, 1983.

INSTITUTO BRASILEIRO DE GEOGRAFIA E ESTATÍSTICA. Cidades: São Luís. 2018. Disponível em: https:// cidades.ibge.gov.br/brasil/ma/sao-luis/panorama Acesso em: 11 nov. 2018.

KLEINE, D. Technologies of Choice? ICTs, development, and the capabilities approach. London: Mit Press, 2013.

LASTRES, H. M. M.; ALBAGLI, S. (Orgs.). Informação e globalização na era do conhecimento. Rio de Janeiro: Campus, 1999.

LEMOS, A. Cibercultura, tecnologia e vida social na cultura contemporânea. Porto Alegre: Sulina, 2004.

LOPES, D. B.; SILVA, L. Cidadania e telenovela: evidências e ocultações na midiatização do social. In: MORIGI, V. J.; GIRARDI, I. M. T.; ALMEIDA, C. D. (Org.). Comunicação, informação e cidadania: refletindo práticas e contextos. Porto Alegre: Sulina, 2011.

NETO, F.; FISCHER, A.; GOUVEA, M. A. A aplicação de técnicas multivariadas na análise dos fatores críticos de sucesso na implementação de iniciativas de eGov na administração tributária paulista. In: SEMINÁRIOS EM ADMINISTRAÇÃO, 7., 10-11 ago. 2004, São Paulo. Anais [...]. São Paulo: USP, 2004.

NEULS, G. Aproximações teóricas entre informação, consumo e cidadania ambiental. In: MORIGI, V. J.; GIRARDI, I. M. T.; ALMEIDA, C. D. (Org.). Comunicação, informação e cidadania: refletindo práticas e contextos. Porto Alegre: Sulina, 2011.

OLIVEIRA, C. B. (Org.). Constituição da República Federativa do Brasil. Rio de Janeiro: Roma Victor, 2002. $320 \mathrm{p}$. 
ORGANIZAÇÃO DAS NAÇÕES UNIDAS [ONU]. Declaração universal dos direitos humanos, de 10 dez. 1948. Portugal: UNIC, 1948. Disponível em: https://www.ohchr.org/EN/UDHR/Pages/Language.aspx?LangID=por. Acesso em: 13 out. 2021.

PERUZZO, C. M. K. Comunicação popular e comunitária em práticas de desenvolvimento rural na região de Borborema (PB-Brasil). Comunicação \& Sociedade, São Bernardo do Campo, v. 37, n. 2, p. 183-208, 2015.

PIENIZ, M.; SILVEIRA, A. C. M. Apropriações da web como meio para o exercício da cidadania: expressões de identidades culturais ligadas ao território. In: MORIGI, V. J.; TOURINHO, I. M. G.; ALMEIDA, C. D. Comunicação, informação e cidadania: refletindo práticas e contextos. Porto Alegre: Sulina, 2011.

QUEBRAL, N. Reflections on development communication (25 years after). Filipinas: University of the Philippines Los Baños, 2002.

SANTOS, M. J.; CARNIELLO, M. F.; OLIVEIRA, E. A. A. Q. Comunicação digital na gestão pública dos municípios da RMVP: acesso à informação, transparência e mecanismos de participação. Revista Brasileira de Desenvolvimento Regional, Blumenau, v. 1, n. 1, p. 167-84, 2013. Disponível em: http://proxy.furb.br/ ojs/index.php/rbdr/article/view/3654/2265. Acesso em: 11 nov. 2018.

SEN, A. Desenvolvimento como liberdade. São Paulo: Companhia das Letras, 2000.

ZÉMOR, P. Como anda a comunicação pública? Revista do Serviço Público Brasileiro, Brasília, v. 60, n. 2, p. 189-95, 2009. Disponível em: https://revista.enap.gov.br/index.php/RSP/article/view/21. Acesso em: 26 set. 2018.

\section{Sobre as autoras:}

Silvia Leticia Araújo de Melo: Mestre em Gestão e Desenvolvimento Regional pela Universidade de Taubaté (UNITAU). Especialista em Língua Portuguesa pelas Faculdades Integradas de Jacarepaguá (FIJ). Graduada em Letras/Língua Portuguesa pela Universidade Estadual do Maranhão (UEMA). Atualmente é assistente em Administração no Instituto Federal do Maranhão (IFMA). E-mail: leticiaitz@ifma.edu.br, Orcid: http://orcid.org/0000-0002-6042-9015

Monica Franchi Carniello: Doutora em Comunicação e Semiótica pela Pontifícia Universidade Católica de São Paulo (PUC-SP). Mestre em Comunicação e Letras pela Universidade Presbiteriana Mackenzie. Especialista em Marketing pela University of California. Graduada em Comunicação Social com habilitação em Publicidade e Propaganda pela Pontifícia Universidade Católica de Campinas (PUC-Campinas). Professora assistente doutora na Universidade de Taubaté (UNITAU) e da Faculdade de Tecnologia de Pindamonhangaba. E-mail: monicafcarniello@gmail.com, Orcid: http://orcid.org/0000-0002-3107-901X 
